\title{
Modalities for Imaging of Prostate Cancer
}

\author{
A. H. Hou, D. Swanson, and A. B. Barqawi \\ Division of Urology, University of Colorado Health Sciences Center, UCDSOM, MS C-319, \\ Academic Office One Bldg., 12631 East 17th Ave., Room L15-5602, Aurora, CO 80045, USA
}

Correspondence should be addressed to A. H. Hou, amy.hou@ucdenver.edu

Received 10 June 2009; Revised 8 September 2009; Accepted 31 December 2009

Recommended by Maxwell V. Meng

Prostate cancer is the second most common cause of cancer deaths among males in the United States. Prostate screening by digital rectal examination and prostate-specific antigen has shifted the diagnosis of prostate cancer to lower grade, organ confined disease, adding to overdetection and overtreatment of prostate cancer. The new challenge is in differentiating clinically relevant tumors from ones that may otherwise never have become evident if not for screening. The rapid evolution of imaging modalities and the synthesis of anatomic, functional, and molecular data allow for improved detection and characterization of prostate cancer. However, the appropriate use of imaging is difficult to define, as many controversial studies regarding each of the modalities and their utilities can be found in the literature. Clinical practice patterns have been slow to adopt many of these advances as a result. This review discusses the more established imaging techniques, including Ultrasonography, Magnetic Resonance Imaging, MR Spectroscopy, Computed Tomography, and Positron Emission Tomography. We also review several promising techniques on the horizon, including Dynamic Contrast-Enhanced MRI, Diffuse-Weighted Imaging, Superparamagnetic Nanoparticles, and Radionuclide Scintigraphy.

Copyright (C) 2009 A. H. Hou et al. This is an open access article distributed under the Creative Commons Attribution License, which permits unrestricted use, distribution, and reproduction in any medium, provided the original work is properly cited.

\section{Introduction}

Prostate cancer is the second most common cause of cancer deaths among males in the United States. The incidence of prostate cancer is relatively constant at 165 cases per 100,000 men. Since 1990, the age-adjusted death rate has progressively decreased by $31 \%$, which is attributed to early detection and treatment [1]. Prostate screening by digital rectal examination (DRE) and prostate-specific antigen (PSA) has shifted the diagnosis of prostate cancer to lower grade, organ confined disease $[2,3]$, adding to overdetection and overtreatment of prostate cancer by at least 30\% [4]. A recent review by Etzioni et al. estimated that $10 \%$ of men with lowgrade prostate cancer were overtreated with radical surgery, and $45 \%$ were overtreated with radiation therapy [5]. With the publication of the 10-year results of the Prostate, Lung, Colorectal, and Ovarian (PLCO) Cancer Screening Trial demonstrating no reduction of mortality with screening, the new challenge is in differentiating clinically relevant tumors from ones that may otherwise never have become evident if not for screening [6].
The rapid evolution of imaging modalities allows for better detection and staging of prostate cancer, thus directing appropriate treatment and follow-up. However, the appropriate use of imaging is difficult to define, as many controversial studies regarding each of the modalities and their utilities can be found in the literature. Here, we will discuss the more established imaging techniques, and will review several promising techniques on the horizon.

\section{Transrectal Ultrasound}

2.1. Grey-Scale Ultrasound. Grey-scale transrectal ultrasound (TRUS) is the most commonly used modality for evaluating the prostate, particularly for guiding needle biopsies. When prostate cancer is suspected due to an elevated PSA or an abnormal digital rectal exam (DRE), the next step is usually a systematic needle biopsy, for which TRUS is integral and effective in identifying the outlines of the prostate in sagittal and transverse planes. It is 
a simple and readily available modality, and can provide fairly accurate estimations of the prostate volume which are important in the determination of PSA density [7]. Prostate cancers typically appear hypoechoic on TRUS [8], and hypoechoic lesions on TRUS are more than twice as likely to contain cancer as isoechoic areas [9]. However, most hypoechoic lesions found on TRUS are not cancer [10]. Moreover, up to $30 \%$ of prostate cancers are isoechoic [11], and approximately $1 \%$ are hyperechoic [8]. The positive predictive value (PPV) of grey-scale TRUS is reported to be $52.7 \%$, and the negative predictive value (NPV) is $72 \%$, with an accuracy of $67 \%$ [12]. Thus, its utility in the detection and localization of prostate cancer is somewhat limited. However, it remains the imaging modality of choice for guided prostate biopsies, as well as for directing brachtherapy, cryotherapy, high-intensity focal ultrasound ablation, and other locallydirected therapies including hyperthermia, photodynamic therapy, tumor vaccines, and gene therapy [13].

The value of TRUS for local staging is controversial, although several studies have established criteria for distinguishing extracapsular extension (ECE) on TRUS, including bulging or irregularity of the capsule adjacent to a hypoechoic lesion [13], as well as length of contact of a lesion with the capsule [14]. A multiinstitutional study found TRUS to be no more accurate than DRE for the purpose of detecting local tumor extension [15], although other early reports found an increased accuracy when ultrasound findings were combined with DRE and PSA level [16]. Other studies have also found poor pathologic correlation and inaccurate prediction of clinical stage with TRUS and have shown that impalpable tumors have similar outcomes regardless of TRUS findings $[17,18]$. However, a more recent study of 620 men who underwent TRUS by a single ultrasonographer prior to radical prostatectomy found that evidence of extra-capsular extension (ECE) by TRUS correlated with a significantly higher pathologic stage [19]. They found that TRUS staging was the most significant predictor of ECE compared with established risk factors such as Gleason grade and serum PSA, and furthermore that TRUS staging performed as well as these other variables in predicting biochemical failure after radical prostatectomy. This study was performed at a single institution by a single highly experienced ultrasonographer, and has yet to be replicated in other reports.

2.2. Contrast-Enhanced Ultrasound. Interest in increasing the sensitivity of ultrasound has led to the development of multiple techniques based on ultrasound but incorporating additional technology. Contrast enhanced TRUS (CEUS) combines the value of traditional ultrasound in spatial and temporal visualization of the prostate with the observation that the process of prostatic tumor growth induces neovascularization [20]. CEUS is a method of measuring the intraprostatic vascular structures using microbubbles as the contrast agent. 1-10 $\mu \mathrm{m}$ gas-encapsulating spheres (microbubbles) are injected into the bloodstream, and then visualized as they flow through the prostate using a transrectal ultrasound probe. The bubbles function as additional reflectors to increase the sensitivity of color and power Doppler [21]. Abnormal findings on CEUS have been found to correlate with cancer on pathologic examination [22].

In the early days of CEUS, when high-energy ultrasonography was used, the majority of the microbubbles were destroyed by the pulsations, hindering visualization of the microvasculature [23]. In recent years, several developments in the technology have led to increased sensitivity of microbubble visualization in the microvasculature of the prostate. Wink et al. recently evaluated the results of multiple European studies which correlated CEUS and histology findings on prostate resection, and concluded that tumor localization using CEUS is a promising technique. The data supports the use of CEUS in aiding in visualization of prostate cancer, but the sensitivity and specificity are not high enough to justify discontinuing systematic prostate biopsies [21].

Using contrast enhanced-ultrasound to target biopsies has been found to detect statistically significantly more cancers with fewer number of cores compared to traditional gray-scale ultrasound-guided biopsy [24]. The same study found a 2.6 fold higher likelihood of detecting prostate cancer when contrast-enhanced ultrasound was used, over grayscale ultrasonography. A study from the Netherlands [25] examined how well was three-dimensional color-enhanced power Doppler ultrasound (3D-CE-PDU)-directed prostate biopsies compared with radical prostatectomy specimens. All patients in the study were known to have prostate cancer and were already scheduled for radical prostatectomy. Overall, $51 \%$ to $63 \%$ of the prostate cancers were detected by contrast-enhanced ultrasound. There was a higher sensitivity $(68 \%-79 \%)$ for detecting cancers with a maximum diameter of $\geq 5 \mathrm{~mm}$. Of note, the study found only $13 \%$ of extracapsular extension or seminal vesicle invasion, demonstrating that $3 \mathrm{D}-\mathrm{CE}-\mathrm{PDU}$ is a poor tool for staging.

2.3. Elastography. Another approach based on TRUS is elastography, which measures the rigidity and elastic properties of the prostate. The prostate is compressed using the transrectal probe, and the differences in tissue strain are used to localize intraprostatic lesions. Similar to the digital rectal exam, areas of increased firmness are more suspicious for malignancy. Pallwein et al. [26] found a sensitivity and specificity of $87 \%$ and $92 \%$ for detecting prostate cancer foci in a study of 15 patients who underwent realtime elastography with subsequent radical prostatectomies. They detected 28 of 35 tumor foci, with highest sensitivity $(100 \%)$ for detecting cancer at the apex. In another study of 137 men who underwent targeted prostate biopsies with elastography with color Doppler, an odds ratio of 1.82 was found, with a significantly higher likelihood of cancer detection than with gray-scale sextant biopsy [27]. A greater than two-fold increased likelihood of malignancy was noted in association with ultrasonic abnormality; abnormal color flow was associated with Gleason 8-10 (OR 4.1210.61). This association was not found in lower-grade lesions with color Doppler. However, abnormal elastographic findings were associated with malignancy for all tumor grades. 
In 2008, Salomon et al. [28] reported on a prospective single institution study of 109 men who were scheduled for radical prostatectomy and underwent ultrasound-based elastography-directed prostate biopsy. The PPV between suspicious areas on elastography and cancerous areas found on pathologic examination after radical prostatectomy was $87.8 \%$, and the NPV was $59 \%$. The sensitivity and specificity of elastography in detecting cancer were $75.4 \%$ and $76.7 \%$ respectively. Specificity increased to $80 \%$ when the lesion was $\geq 5 \mathrm{~mm}$ in diameter. Another study of 107 men with PSA $>4 \mathrm{ng} / \mathrm{mL}$ or abnormal digital rectal examinations who underwent elastographic studies, regular transrectal ultrasound, and power Doppler ultrasonography, found the sensitivity of elastrography to be similar to that of power Doppler (68\% versus 70\%) and higher than regular ultrasound (50\%), with a specificity of $81 \%$ [29]. Overall, elastography seems to be a feasible, reproducible tool with fairly good sensitivity for detecting prostate cancer. Further clinical studies to clarify the role of elastography in the detection of prostate cancer and its use in guiding prostate biopsies are ongoing.

2.4. Computer-Aided Ultrasonography. Computer-aided ultrasonography, also known as HistoScanning, allows mapping of prostatic morphology, and identification of malignant lesions by characterizing and quantifying the disorganization of the tissue. Theoretically, malignancy will induce disorganization, and computer-aided ultrasonography will detect these changes by extracting this data from background ultrasonographic data. In a study of 29 patients who underwent radical prostatectomy after Histoscanning, a close correlation between prostate HistoScanning analysis and pathologic findings was found. The test was capable of localizing tumors and determining their cross-sectional size with fairly good accuracy, as well as identifying multifocality, bilaterality, and extraprostatic extension. The authors of the study propose that HistoScanning is an inexpensive, noninvasive test with reasonable accuracy that could further guide clinical decision making when it comes to selecting men with high PSAs to undergo prostate biopsy [30]. However, further studies to validate this data are lacking.

\section{Magnetic Resonance Imaging}

3.1. T2-Weighted Magnetic Resonance Imaging. The role of standard T2-weighted MRI in the diagnosis and staging of prostate cancer is still evolving and varies from center to center. Generally, MRI has a fairly good sensitivity but poor specificity [31-33]. A recent meta-analysis of studies correlating MRI and histopathology found reported sensitivities between $37 \%$ and $96 \%$ for detecting prostate cancer, with differences due to variable definitions of cancer, exclusion of transitional zone cancers, and criteria used for positive findings [34]. Specificity ranged from $21 \%$ to $67 \%$ in this meta-analysis, although the authors note that specificity is difficult to assess due to inherent group selection bias in these studies.

The specificity of MRI is decreased by its inability to distinguish the low T2 signal intensity that is associated with tumor from other pathologies such as prostatitis, postbiopsy hemorrhage, or treatment changes [35]. Generally, a delay of three to four weeks between prostate biopsy and MRI was recommended [36, 37], although a more recent study recommended a delay of six to eight weeks when more biopsy cores are taken due to a higher degree of hemorrhage [38].

Detection of prostate cancer in the transitional zone was thought to be inferior. A study by Ellis et al. found that MRI missed 78 of 79 tumors in the anterior gland that were $>5 \mathrm{~mL}$ in volume, although this study was done without the use of endorectal MRI [39]. Other studies have shown that MRI has roughly equal accuracy throughout the prostate [35] , and that MRI has good sensitivity and specificity ( $75 \%$ and $87 \%$ ) in detecting transitional-zone cancers as well [40]. Akin et al. [40] suggested that several indicators of transitional zone cancer include homogenous low signal, lenticular shape, and invasion of the anterior fibromuscular stroma.

3.1.1. Screening. Many possible applications of MRI have been proposed and studied. Some argue that it can contribute to the screening process. In patients with a positive PSA screening test but a negative biopsy, a negative MRI result may eliminate the need for repeat biopsy by increasing the NPV of a negative prostate biopsy. In a screening population of 92 patients, Comet-Batlle et al. demonstrated an NPV for cancer on subsequent transrectal biopsy of 91\% [41], which is comparable to the $85 \% \mathrm{NPV}$ of a negative octant biopsy [42]. Cheikh et al. reported an $82.6 \%$ sensitivity and $100 \%$ NPV of T2-weighted or dynamic contrast-enhanced MRI when evaluating visible suspicious areas prior to repeat TRUS prostate needle biopsy [43]. Beyersdroff et al. studied a population of 44 men who had elevated PSA but negative initial biopsy, and found that in retrospective analysis of MRI after a repeat biopsy was performed, MRI imaging results did not correlate with biopsy findings [31]. To the authors, this confirmed that MRI has a fairly low specificity and is subject to error due to prostatitis, fibrosis, or intraepithelial neoplasia. The widespread use of MRI for screening purposes has not been implemented despite several promising studies, largely due to the high costs, although its use in selected patients may be warranted after negative prostate biopsies.

3.1.2. MRI-Guided Prostate Biopsy. The use of MRI to guide prostate biopsies has also been proposed and is currently under investigation and development. Beyersdroff et al. published reports of successful MRI-guided prostate biopsy, noting that the technique was time-consuming and required specific equipment, and was very susceptible to prostate movement during biopsy [44]. Multiple groups are experimenting with needle-positioning devises and robotic manipulators to facilitate MRI-guided biopsies [45]. However, routine use of MRI to guide prostate biopsy is not recommended with existing evidence, due to expense and the time-consuming nature; although with further developments and experience, there may be indications for MRIguided biopsies in patients with previous negative TRUSguided biopsies. 
3.1.3. Preoperative Assessment. Recently, MRI has been evaluated for its utility in preoperative assessment prior to prostatectomy. Hricak et al. found that by reviewing preoperative endorectal MR images, surgeons were more accurately able to decide whether or not to preserve the neurovascular bundle during surgery [46]. 135 patients were evaluated with MRI preoperatively and judged by a surgeon and radiologist, then compared to surgeon's clinical judgement during surgery and to histopathologic findings. They found that when the surgeon decided to spare the NVB, MRI confirmed that decision in $84 \%$ of cases, and was correct in $96 \%$ of the time. MRI results changed the surgical plan in $78 \%$ of high-risk patients ( $>75 \%$ risk of ECE on Partin tables), and was correct in $93 \%$ of cases. These results were supported by a recent study from Scandanavia of 75 patients, which showed a sensitivity of $92 \%$ and specificity of $100 \%$ for detection of ECE/NVB involvement with preoperative MRI [47]. MRI findings favored NVB preservation in $67 \%$ of patients with a high-clinical probability of ECE, and opposed NVB preservation in $33 \%$ of patients with low probability, and was correct in $100 \%$ of the time. Another series showed that prominence of apical periprostatic veins on preoperative endorectal MRI was significantly associated with intraoperative blood loss [48]. These studies support the use of MRI for preoperatively assessing patients, particularly regarding the decision to spare or resect the neurovascular bundles.

3.1.4. Staging. Due to many advances in technology, MRI is now considered by many to be the most exact imaging modality for staging prostate cancer, including pelvic lymph node and pelvic bony metastases [49-53], although studies have found that there is significant intraobserver variability in the use of MRI for detecting prostate cancer [54]. Several early studies found that the sensitivity of MRI in detecting extra-capsular extension was limited [55-57]; however, developments in technology have improved the accuracy for local staging. The use of endorectal-body phased array coils, as opposed to a torso phases-array coils, has been shown to offer superior staging accuracy [58]. This technique improves the spatial resolution and signal-to-noise ratio of prostate MRI [31]. Endorectal MRI has been found to have high negative and positive predictive values, as well as good accuracy in predicting extracapsular invasion $[58,59]$. Two meta-analyses of staging accuracy with endorectal MRI have been conducted, with differing results; one found that endorectal MRI improved staging performance [60], whereas the other found the opposite [61].

Other recent developments have improved the accuracy of T2-weighted MRI in local staging as well, including faster imaging sequences, postprocessing image correction, and more powerful coils $[58,62,63]$. The use of persextant localization is another development in MRI technology that has allowed more efficient communication of data [35, 64]. Theoretically, a 3Tesla endorectal coil should provide improved signal-to-noise ratio and improve image quality, and several early reports do report significantly improved staging performance, with sensitivities of $73-88 \%$ and specificities of $96-100 \%[65,66]$. However, this technology is not widely available, and more studies are needed before widespread implementation.

Despite these technological advances, the use of MRI for staging prostate cancer is still fairly controversial, and its use at different institutions is still evolving. Several studies have focused on the utility of MRI across different risk groups in an attempt to solve the issue of which patient population should undergo preoperative MRI for staging. It has been found that the inclusion of MRI in clinical nomograms increases the prediction of local tumor extent in all risk groups [67]. Engelbrecht et al. have suggested that in patients with an intermediate risk of having stage T3 disease, as predicted by having a PSA of $4-20 \mathrm{ng} / \mathrm{mL}$ and a Gleason score between 5 and 7, MRI is advised because the treatment decision may depend on imaging results [68]. Another group found that $26 \%$ of low-risk patients, with PSA $<10 \mathrm{ng} / \mathrm{mL}$ and Gleason 2-7 or PSA $10.1-20 \mathrm{ng} / \mathrm{mL}$ and Gleason 2-5, had histopathologic proof of ECE or SVI seen on MRI prior to surgery [63], which may indicate justification of routine MRI in this group as well. Furthermore, The American Joint Commission on Cancer currently recommends either CT or MRI in the high-risk group, with PSA $>20$ or Gleason $>7-8$ [69].

Those who argue against its routine use in preoperative evaluation cite its expense and questionable utility. D'Amico et al. suggested that although MRI does increase the prediction of biochemical failure in a significant number of patients, the high cost of routine use of MRI is not justified in light of questionable effect on decreasing unnecessary surgeries [70]. Another study by May et al. evaluating at the ability of endorectal MRI to detect and stage prostate cancer concluded that due to poor sensitivity and specificity, high intraobserver variability, and a tendency to overstage cancer, MRI results should not result in alteration of treatment decisions [71].

3.2. Magnetic Resonance Spectroscopic Imaging. Intraprostatic tumor growth is associated with increased cell membrane turnover and increased cell proliferation, which lead to altered relative concentrations of certain metabolites including creatine, choline, and citrate, most specifically an increase in choline and a decrease in citrate. Magnetic resonance spectroscopy (MRSI) is a technology that increases the sensitivity and specificity of MRI by analyzing this metabolic profile of discreet voxels within the prostate [72, 73]. The largest study comparing MRSI to MRI, by Wefer et al., found that MRSI alone had a higher sensitivity (76\%) than T2-weighted MRI (67\%), but a lower specificity. However, this and other studies have found that the accuracy in diagnosing prostate cancer is the highest when anatomic information from MRI and metabolic information from MRSI are combined [35, 72, 74]. Another study combined data from MRI/MRSI with clinical and pathological data, and found that a combined model was superior to purely clinical models at predicting the probability of insignificant prostate cancer [75].

More recently, several studies have analyzed the effects of adding data from MRI/MRSI to the staging normograms. In a study of 229 patients who underwent MRI and 383 who 
underwent combined MRI/MRSI prior to radical prostatectomy, the radiologic findings contributed significant value to the standard normogram for predicting prostate-confined disease [67].

Spectroscopy has several other advantages over traditional MRI. The ability of MRSI to detect transition zone tumors has been reported to be $80 \%$, significantly higher than T2-weighted MRI [40]. Coakley et al. [76] explored the ability of MRSI to estimate the volume of prostate cancer, and found improved accuracy in volume measurements when spectroscopy is added to MRI. Yu et al. also demonstrated that use of spectroscopic imaging decreases interobserver variability, and for less experienced radiologists, improved the detection of ECE [49].

A recent multiinstitutional study of 134 men with biopsy-proven prostate cancer who underwent combined MRSI/MRI found somewhat disheartening results [77]. When compared to endorectal MRI, combined MRSI/MRI showed no demonstrable benefit. This study was specifically conducted with inexperienced operators, and was focused on low-risk patients with small disease burden, representative of the screened American population.

3.2.1. Tumor Aggressiveness. MRSI has potential as a noninvasive method of assessing tumor aggressiveness, as it has a higher sensitivity in detecting cancers of higher grade [78]. Zakian et al. studied the relationship between Gleason grade as a measure of tumor aggressiveness and MRSI volumetric and metabolic data, and found that the ratio of creatine plus choline to citrate, which is a ratio that is known to be positively correlated with prostate cancer, can predict the aggressiveness of the tumor. This study also found that MRSI detected only $44 \%$ of Gleason $3+3$ tumors, compared to $90 \%$ of Gleason $>7$ cancers. Thus, spectroscopic information may contribute to the decision-making process by providing information about tumor aggressiveness.

3.2.2. Additional Uses. Additional uses of MRSI in prostate cancer have been proposed, including supplementing biopsies as a method of detecting both primary and recurrent cancers [34, 35], and as a tool to guide biopsies [79, 80]. Due to the higher sensitivity of MRSI in detecting cancer than sextant biopsies, especially when localized to the apex where biopsies may not sample [35], it may be an adequate method of following patients who have undergone ablative therapy. One study found that MRSI detected all recurrent foci of tumor in 25 patients who had undergone cryotherapy for prostate cancer [81]. Another study of 9 patients with recurrent prostate cancer after external beam radiation therapy found that MRSI and MRI were both superior to biopsy at detecting recurrent disease, with sensitivities of $77 \%$ and $68 \%$, respectively [79]. However, they also found that the specificity of MRSI (78\%) was significantly lower than regular MRI, DRE, or sextant biopsy, which was attributed to postradiation metabolic changes in the normal prostate. The authors suggested that MRSI may be used to supplement other techniques to detect recurrent cancer, to guide biopsies, or to guide treatment by providing localization of tumor [79].
3.3. Dynamic Contrast-Enhanced MRI. Dynamic contrastenhanced-MRI (DCE-MRI) measures the vascularity of prostatic tissue using temporal differences in the uptake of intravenously-administered low molecular weight contrast to distinguish between benign tissue and tumor. Increased microvessel density is seen in $\mathrm{BPH}$, prostatic intraepithelial neoplasia, and prostate cancer [82], and has been found to correlate with disease-specific survival and progression after treatment [83]. Several microvascular features are characteristics of prostate cancer, including heterogenic structure, arterio-venous shunting, vascular tortuosity, intermittent flow, high permeability, and poorly formed vessels [82]. Using various MR sequences, especially T1-weighting [84], these characteristics can be visualized and quantified.

The use of DCE-MRI for primary detection, localization, and staging of prostate cancer has been studied by several groups, with promising results. Jager et al. initially found that the use of DCE-MRI increased the sensitivity for detecting prostate from $57 \%$ with T2-weighted MRI to $73 \%$, with no change in specificity [85]. They also noted that DCEMRI may improve sensitivity for detecting ECE, and that this technology may improve estimations of tumor volume. Other studies have confirmed that DCE adds significantly to the sensitivity for detecting prostate cancer over other modalities [86-89] and that it is fairly accurate in detecting ECE $[90,91]$. A recent prospective study found that DCEMRI had higher localization accuracy than T2-weighted MRI or MRSI in both the central and peripheral glands [92]. When compared to transrectal power-dopper ultrasound, DCE-MRI was found to be significantly more sensitive for detecting cancer in the peripheral zone [89]. Namimoto et al. confirmed that DCE-MRI is useful in the differentiation of peripheral-zone lesions, and also found higher diagnostic accuracy when dynamic MR results were combined with postcontrast T1-weighted images [93]. Other proposed uses for DCE-MRI that include detection of recurrence and follow-up after ablative therapy or androgen deprivation [82].

There is a potential for DCE to predict pathologic grade of prostate cancer, given that microvessel density has been found to correlate with Gleason score [94, 95]. Schlemmer et al. noted that time to onset of the enhancement curve was significantly different in high-grade tumors compared to low-grade tumors [86]. Another study using pathologic specimens for correlation did not find any correlation between enhancement times and pathologic grade [96].

Kim and Park speculated that DCE-MRI may benefit immensely from the advent and institution of 3 Tesla due to increased signal-to-noise ratio and because of the T1 properties of prostate tissue [97]. An early study found that at 3 Tesla, DCE-MRI has a higher accuracy and sensitivity, although a lower specificity, than T2-weighted imagining, and concluded that DCE-MRI may thus be more useful for diagnosis and preoperative staging [51]. Fütterer et al. found that DCE-MRI at 3 Tesla was superior to 1.5 Tesla in regards to delineation of prostate cancer, extra-capsular extension, and visualization of the peripheral zone and central zone [98]. They found an overall staging accuracy of $83 \%$ at 1.5 Tesla, and $100 \%$ at 3 Tesla. 
It is clear that more studies are needed the define to role of DCE-MRI in the evaluation of prostate cancer. Major limitations of this technology include the inability to differentiate between prostatitis and prostate cancer in the peripheral zone and between $\mathrm{BPH}$ and cancer in the central zone [99]. With current evidence, it has been proposed that DCE-MRI can be used in combination with T2weighted MRI, MRSI, and DWI as part of an assessment of cancer probability, to guide targeted rebiopsy [82], and to preoperatively stage patients with prostate cancer $[51,91]$.

\subsection{Diffusion-Weighted Imaging MRI. Diffusion-weighted} imaging (DWI) is a method of obtaining molecular and cellular information about the prostate, specifically regarding the movement and functional environment of water in prostate tissue. By measuring the microdiffusion of water in the intracellular and extracellular spaces, DWI can calculate an apparent diffusion coefficient, which reflects compartmental shifts in water, membrane permeability, and cellular density, all of which may be altered in cancerous tissue [100]. Prostate cancer has a lower apparent diffusion coefficient than does normal prostate tissue, both in the peripheral zone [101] and in the transition zone [102], which indicates a reduction in flow or diffusion of water. This is attributed primarily to an increase in cellularity in this tissue $[101,102]$.

Several studies have analyzed the value of adding DWI to T2-weighted MRI and MRSI, and have generally found increased sensitivity $(54 \%-98 \%)$ and specificity (58\%$100 \%)[100,103,104]$. Kim et al. recently found that combined DWI/T2WI is more sensitive for predicting recurrent cancer after radiation therapy than T2WI alone [105]. DWI has also been found to increase the accuracy of peripheral zone tumor volume measurements [106]. Park et al. recently reported that DWI may be useful in the evaluation of patients with persistently elevated PSA values but negative prostate biopsies, as it was more sensitive than T2-weighted MRI in localizing lesions [107].

Major limitations of this technology include a substantial overlap of ADC values between malignant tissue and normal prostate and a marginal signal-to-noise ratio [105]. Modern 3Tesla MRI systems are under investigation for their utility in increasing signal-to-noise ratios for DWI. Early studies with this technology report a high sensitivity (94\%) and specificity (91\%) in the peripheral zone, and a similarly high sensitivity (90\%) and specificity (84\%) in the transition zone [108]. Future research will further elucidate the role of DWI in the diagnosis and staging of prostate cancer, although preliminary studies are very promising.

3.5. Superparamagnetic Nanoparticles. Another MRI-based technology currently under active investigation is the use of lymphotropic superparamagnetic nanoparticles as a contrast agent to detect small and otherwise undetectable nodal metastases. This material is injected intravenously and is taken up by macrophages in normal lymph nodes, creating a contrast between these nodes and cancerous nodes where the macrophages have been replaced by tumor cells [109]. The technology does not rely on the size or shape of the lymph node, criteria on which traditional radiographic staging is based, and is thus suspected to be more accurate in detecting metastases especially in normal-sized nodes. It has been proven to be effective in several other cancers [109]. Investigations into its use in prostate cancer are ongoing. Harisinghani et al. found that lymphotropic nanoparticleenhanced MRI (LNMRI) can detect metastases in small lymph nodes that would be considered benign on CT or unenhanced MRI, and that metastatic nodes were found outside of the classical field of lymph node dissection in a significant number of patients [110]. This study evaluated 80 patients with LNMRI prior to either pelvic lymphadectomy or diagnosis of metastases with CT, and found that the addition of superparamagnetic nanoparticles increased sensitivity of MRI from $45.4 \%$ to $100 \%$ with a specificity of $95.7 \%$. It has been suggested that this technology may be of particular utility in patients who have high risk of metastatic disease on the basis of standard staging nomograms and conventional MRI, both of which offer fairly high negative predictive values for the detection of metastatic disease [13].

This technology may also be useful in detecting recurrent cancer, as well as guiding targeted radiation therapy. A recent study reported that in 26 patients with recurrent prostate cancer after radical prostatectomy, all of whom were candidates for salvage radiation therapy, LNMRI detected positive nodes in 6 patients, none of whom had enlarged nodes on axial imaging [111]. Further studies are needed before this promising but experimental technology enters wide-spread use.

\section{Computed Tomography}

At this time, CT has very little role in the diagnosis of prostate cancer or in staging of known cancers in patients with a low clinical suspicion of metastatic disease [13]. CT detects nodal metastases based on size, and in general CT has a very low diagnostic yield in low-risk patients due to a low incidence of large nodal metastases in these patients. The primary role of CT in prostate cancer is in staging for patients with suspected metastatic disease, for which is has variable sensitivity and specificity $[112,113]$. O'Dowd et al. [114] recommend that CT be used for high-risk patients with PSA > $20 \mathrm{ng} / \mathrm{mL}$, Gleason score $>7$, or at least clinical stage T3 disease. For the purpose of detecting pelvic lymph node metastases, the sensitivity has been reported from $25 \%$ [115] to $85 \%$ [116], but is generally approximately 36\% [117], which is not sufficiently accurate to justify widespread use except for selected high-risk patients. Similarly, for diagnosing bone metastases, CT is inferior to other modalities such as bone scans and MRI, and should not be widely used [13] .

\section{Positron Emission Tomography}

The theory behind positron emission tomography (PET) is that prostate cancer, having a high metabolic rate, will consume glucose through the glycolytic pathway, which is associated with higher glucose uptake. PET uses a radiolabeled analogue of glucose, typically fluorodeoxyglucose 
(FDG), as a tracer to measure the metabolic rate of the tissue, and attempts to identify cancerous lesions based on their increased metabolism. Despite initial enthusiasm for PET as a diagnostic modality for prostate cancer, studies have shown mediocre results, with suboptimal sensitivity $[118,119]$. Effert et al. found that they were unable to differentiate between primary prostate cancer and benign prostatic hypertrophy with FDG PET [120], as both exhibit increased metabolism. This is thought to be due to a lower rate of growth and thus lower level of radiotracer uptake by prostate cancers than by other cancers in the body for which PET has been found to be more useful [121]. Moreover, as FDG is excreted by the kidneys, it tends to accumulate in the bladder and the prostatic urethra, thus masking uptake by the prostate [121]. Even when this was compensated for by diuresis with furosemide prior to PET scan [122] or continuous bladder irrigation, sensitivity was not sufficient to reliably detect prostate cancer or for the detection of lymph node metastases [123].

Other radiotracers with different properties are being investigated. Several studies have used ${ }^{11}$ Carbon- and ${ }^{18}$ Fluoride-based agents, including ${ }^{11}$ Carbon-methionine, ${ }^{18} \mathrm{~F}$-Fluorocholine, ${ }^{11}$ Carbon-choline, and ${ }^{11}$ Carbon-acetate, as tracers for detecting prostate cancer. These tracers are radiolabeled amino acids which are concentrated in lesions with high protein synthesis rates, and can theoretically be used to identify cancerous lesions. They are used in the diagnosis of many different cancers, with sound clinical background, and are undergoing further testing for use in the primary diagnosis of prostate cancer, with limited utility at this point due to inadequate accuracy [72, 124-126]. Moreover, due to rapid decay of ${ }^{11}$ Carbon, the use of these agents necessitates a local cyclotron, limiting its widespread availability.

Several studies have evaluated the use of PET for the staging of prostate cancer. Schiavina et al. [127] found that ${ }^{11} \mathrm{C}$-choline PET performed better than clinical nomograms for predicting nodal metastases, with a sensitivity and specificity of $60 \%$ and $98 \%$. Results from a study by Husarik at al. [128] found more discouraging staging accuracy with ${ }^{18} \mathrm{~F}$-FCH PET, with only one in five histopathologicallyconfirmed metastatic lymph nodes detected by imaging.

The most promising results with PET/CT are in the field of detecting recurrent disease after primary therapy for prostate cancer [129]. Rinnab et al. found first that ${ }^{11} \mathrm{C}$-choline was useful for targeted salvage lymph node dissection after treatment for prostate cancer [130], and then more recently that ${ }^{11} \mathrm{C}$-choline has a high sensitivity (93\%) and PPV (80\%) for detecting local recurrence or distant metastases [131]. This more recent study confirmed the results of several previous studies $[132,133]$ that PET/CT using ${ }^{11} \mathrm{C}$-choline may be a useful approach for detecting and localizing recurrent disease, but also showed that integrated PET/CT systems may be particularly helpful at low PSA levels.

The future of PET/CT in the field of prostate cancer is bright, with many developments on the horizon, from new tracers and technology to novel reading techniques. Li et al. recently reported that using a ratio of uptake values between prostate tissue and muscle as a primary measurement, ${ }^{11} \mathrm{C}$ choline PET achieved a sensitivity and specificity of $90 \%$ and $86 \%$, may be a feasible technique to differentiate benign from malignant prostate lesions. Nuñez has proposed a combined use of FDG and ${ }^{11} \mathrm{C}$-methionine based on a temporal cascade of metabolic activity, with increased uptake of ${ }^{11} \mathrm{C}$-methionine in the early stages of cancer followed by relatively higher uptake of FDG during more advanced cancer stages [134]. Another group recently reported on the combined use of ${ }^{11} \mathrm{C}$-Choline and $\mathrm{FDG}$ for the detection of cancer after biochemical recurrence, and reported a sensitivity of $80 \%$ when a PSA cutoff of $1.9 \mathrm{ng} / \mathrm{mL}$ was used [135]. Hricak et al. suggested that novel iterative imagine reconstruction techniques will help to reduce artifact [13]. Several groups are also looking at new radiotracers that incorporate antibodies targeting molecules such as prostatespecific membrane antigen, which may significantly increase specificity of PET/CT $[136,137]$.

\section{Radionuclide Scintigraphy}

Prostascint is an immunoscintigraphic diagnostic mode utilizing [111] indium-capromab pendetide, a radiolabeled murine monoclonal antibody that is reactive with prostate-specific membrane antigen (PSMA), a glycoprotein expressed by prostate tissue. Images are captured with a SPECT gamma camera. It was approved by the FDA in 1996 for the detection of recurrent prostate cancer in soft tissue [138], with a reported sensitivity and specificity of $62 \%$ and 72\% [139]. Seltzer et al. compared helical CT, PET, and Prostascint to evaluate for lymph node metastasis in patients with PSA recurrence. They found that Prostascint had a lower detection rate of metastatic disease than CT or PET [140]. Nagda et al. [141] performed a retrospective review of 58 patients who had rising PSA levels after prostatectomy but negative CT-scans and underwent a capromab pendetide scan. The PPV in detecting disease outside the prostate was $27 \%$. The PPV for detecting prostatic fossa recurrence was $50 \%$. Scan status was not found to be predictive of worsened biochemical recurrence free survival, indicating that decisions for adjuvant radiation therapy for biochemical recurrence should not be based upon the findings of the capromab study alone. Another study by Koontz et al. likewise did not find a difference in progression-free survival in patients with biochemical recurrences depending on findings of capromab scans. A major limitation of this technology is that the antibody targets an epitope that is only exposed by cancer cells that are dead or dying, which thus limits its sensitivity $[142,143]$. The use of capromab studies varies from institution to institution, and more experience is needed before recommendations are solidified.

\section{Conclusion}

We have described some of the recent advances in the field of imaging of prostate cancer, and highlighted some of the many new technologies on the horizon that will further enable rapid and effective diagnosis, staging, and followup of prostate cancer. With new modalities for visualizing 
prostate cancer, we are better than ever before able to characterize and localize lesions, and we are learning how to apply these capabilities to improved treatment decisions and more effective follow-up. These advances will hopefully contribute to improved long-term outcomes.

\section{References}

[1] A. Jemal, R. Siegel, E. Ward, T. Murray, J. Xu, and M. J. Thun, "Cancer statistics, 2007," CA: A Cancer Journal for Clinicians, vol. 57, no. 1, pp. 43-66, 2007.

[2] E. D. Crawford and A. B. Barqawi, "Targeted focal therapy: a minimally invasive ablation technique for early prostate cancer," Oncology, vol. 21, no. 1, pp. 27-32, 2007.

[3] M. R. Cooperberg, J. W. Moul, and P. R. Carroll, "The changing face of prostate cancer," Journal of Clinical Oncology, vol. 23, no. 32, pp. 8146-8151, 2005.

[4] V. Scattoni, A. Zlotta, R. Montironi, C. Schulman, P. Rigatti, and F. Montorsi, "Extended and saturation prostatic biopsy in the diagnosis and characterization of prostate cancer: a critical analysis of the literature," European Urology, vol. 52, pp. 1309-1322, 2007.

[5] R. Etzioni, D. F. Penson, J. M. Legler, et al., "Overdiagnosis due to prostate-specific antigen screening: lessons from U.S. prostate cancer incidence trends," Journal of the National Cancer Institute, vol. 94, no. 13, pp. 981-990, 2002.

[6] G. L. Andriole, R. L. Grubb, S. S. Buys, et al., "Mortality results from a randomized prostate-cancer screening trial," The New England Journal of Medicine, vol. 360, no. 13, pp. 1310-1319, 2009.

[7] M. K. Terris and T. A. Stamey, "Determination of prostate volume by transrectal ultrasound," Journal of Urology, vol. 145, no. 5, pp. 984-987, 1991.

[8] K. Shinohara, T. M. Wheeler, and P. T. Scardino, "The appearance of prostate cancer on transrectal ultrasonography: correlation of imagining and pathological examinations," Journal of Urology, vol. 142, no. 1, pp. 76-82, 1989.

[9] W. J. Ellis, M. P. Chetner, S. D. Preston, and M. K. Brawer, "Diagnosis of prostatic carcinoma: the yield of serum prostate specific antigen, digital rectal examination and transrectal ultrasonography," Journal of Urology, vol. 152, no. 5, pp. 1520-1525, 1994.

[10] H. B. Carter, U. M. Hamper, S. Sheth, et al., "Evaluation of transrectal ultrasound in the diagnosis of prostate cancer," The Journal of Urology, vol. 142, p. 1008, 1989.

[11] F. Lee, J. M. Gray, and R. D. McLeary, “Transrectal ultrasound in the diagnosis of prostate cancer: location, echogenicity, histopathology, and staging," Prostate, vol. 7, no. 2, pp. 117129, 1985.

[12] E. Kuligowska, M. A. Barish, H. M. Fenlon, and M. Blake, "Predictors of prostate carcinoma: accuracy of gray-scale and color Doppler US and serum markers," Radiology, vol. 220, no. 3, pp. 757-764, 2001.

[13] H. Hricak, P. L. Choyke, S. C. Eberhardt, S. A. Leibel, and P. T. Scardino, "Imaging prostate cancer: a multidisciplinary perspective," Radiology, vol. 243, no. 1, pp. 28-53, 2007.

[14] O. Ukimura, P. Troncoso, E. I. Ramirez, and R. J. Babaian, "Prostate cancer staging: correlation between ultrasound determined tumor contact length and pathologically confirmed extraprostatic extension," Journal of Urology, vol. 159, no. 4, pp. 1251-1259, 1998.

[15] J. A. Smith Jr., P. T. Scardino, M. I. Resnick, A. D. Hernandez, S. C. Rose, and M. J. Egger, "Transrectal ultrasound versus digital rectal examination for the staging of carcinoma of the prostate: results of a prospective, multi-institutional trial," Journal of Urology, vol. 157, no. 3, pp. 902-906, 1997.

[16] M. Ohori, S. Egawa, K. Shinohara, T. M. Wheeler, and P. T. Scardino, "Detection of microscopic extracapsular extension prior to radical prostatectomy for clinically localized prostate cancer," British Journal of Urology, vol. 74, no. 1, pp. 72-79, 1994.

[17] H. Augustin, M. Graefen, J. Palisaar, et al., "Prognostic significance of visible lesions on transrectal ultrasound in impalpable prostate cancers: implications for staging," Journal of Clinical Oncology, vol. 21, no. 15, pp. 2860-2868, 2003.

[18] M. Ohori, M. W. Kattan, T. Utsunomiya, K. Suyama, P. T. Scardino, and T. M. Wheeler, "Do impalpable stage T1c prostate cancers visible on ultrasound differ from those not visible?" Journal of Urology, vol. 169, no. 3, pp. 964-968, 2003.

[19] M. L. Eisenberg, J. E. Cowan, B. J. Davies, P. R. Carroll, and K. Shinohara, "The importance of tumor palpability and transrectal ultrasonographic appearance in the contemporary clinical staging of prostate cancer," Urologic Oncology. In press.

[20] R. J. A. Van Moorselaar and E. E. Voest, "Angiogenesis in prostate cancer: its role in disease progression and possible therapeutic approaches," Molecular and Cellular Endocrinology, vol. 197, no. 1-2, pp. 239-250, 2002.

[21] M. Wink, F. Frauscher, D. Cosgrove, et al., "Contrastenhanced ultrasound and prostate cancer; a multicentre European research coordination project," European Urology, vol. 54, no. 5, pp. 982-993, 2008.

[22] D. Strohmeyer, F. Frauscher, A. Klauser, et al., "Contrastenhanced transrectal color Doppler ultrasonography (TRCDUS) for assessment of angiogenesis in prostate cancer," Anticancer Research, vol. 21, no. 4, pp. 2907-2913, 2001.

[23] E. J. Halpern, L. Verkh, F. Forsberg, L. G. Gomella, R. F. Mattrey, and B. B. Goldberg, "Initial experience with contrast-enhanced sonography of the prostate," American Journal of Roentgenology, vol. 174, no. 6, pp. 1575-1580, 2000.

[24] M. Mitterberger, W. Horninger, A. Pelzer, et al., "A prospective randomized trial comparing contrast-enhanced targeted versus systematic ultrasound guided biopsies: impact on prostate cancer detection," Prostate, vol. 67, no. 14, pp. 15371542, 2007.

[25] J. P. M. Sedelaar, G. J. L. H. van Leedners, et al., "Value of contrast US in the detection of significant prostate cancer: correlation with radical prostatectomy specimens," Prostate, vol. 53, pp. 246-253, 2002.

[26] L. Pallwein, M. Mitterberger, P. Struve, et al., "Real-time elastography for detecting prostate cancer: preliminary experience," BJU International, vol. 100, no. 1, pp. 42-46, 2007.

[27] E. D. Nelson, C. B. Slotoroff, L. G. Gomella, and E. J. Halpern, "Targeted biopsy of the prostate: the impact of color doppler imaging and elastography on prostate cancer detection and Gleason score," Urology, vol. 70, no. 6, pp. 1136-1140, 2007.

[28] G. Salomon, J. Kollerman, I. Thederan, et al., "Evaluation of $\mathrm{CaP}$ detection with US real-time elastography: a comparison with step section pathological analysis after radical prostatectomy," European Urology, vol. 54, no. 6, pp. 1354-1362, 2008.

[29] K. Kamoi, K. Okihara, A. Ochiai, et al., "The utility of transrectal real-time elastography in the diagnosis of prostate cancer," Ultrasound in Medicine and Biology, vol. 34, no. 7, pp. 1025-1032, 2008.

[30] J. Braeckman, P. Autier, C. Garbar, et al., "Computer-aided ultrasonography (HistoScanning): a novel technology for 
locating and characterizing prostate cancer," BJU International, vol. 101, no. 3, pp. 293-298, 2008.

[31] D. Beyersdorff, M. Taupitz, B. Winkelmann, et al., "Patients with a history of elevated prostate-specific antigen levels and negative transrectal US-guided quadrant or sextant biopsy results: value of MR imaging," Radiology, vol. 224, no. 3, pp. 701-706, 2002.

[32] J. C. Presti Jr., H. Hricak, P. A. Narayan, K. Shinohara, S. White, and P. R. Carroll, "Local staging of prostatic carcinoma: comparison of transrectal sonography and endorectal MR imaging," American Journal of Roentgenology, vol. 166, no. 1, pp. 103-108, 1996.

[33] M. Mullerad, H. Hricak, K. Kuroiwa, et al., "Comparison of endorectal magnetic resonance imaging, guided prostate biopsy and digital rectal examination in the preoperative anatomical localization of prostate cancer," Journal of Urology, vol. 174, no. 6, pp. 2158-2163, 2005.

[34] A. P. S. Kirkham, M. Emberton, and C. Allen, "How good is MRI at detecting and characterising cancer within the prostate?" European Urology, vol. 50, no. 6, pp. 1163-1175, 2006.

[35] A. E. Wefer, H. Hricak, D. B. Vigneron, et al., "Sextant localization of prostate cancer: comparison of sextant biopsy, magnetic resonance imaging and magnetic resonance spectroscopic imaging with step section histology," Journal of Urology, vol. 164, no. 2, pp. 400-404, 2000.

[36] S. White, H. Hricak, R. Forstner, et al., "Prostate cancer: effect of postbiopsy hemorrhage on interpretation of MR images," Radiology, vol. 195, no. 2, pp. 385-390, 1995.

[37] S. Ikonen, L. Kivisaari, T. Vehmas, et al., "Optimal timing of post-biopsy MR imaging of the prostate," Acta Radiologica, vol. 42, no. 1, pp. 70-73, 2001.

[38] A. Qayyum, F. V. Coakley, Y. Lu, et al., "Organ-confined prostate cancer: effect of prior transrectal biopsy on endorectal MRI and MR spectroscopic imaging," American Journal of Roentgenology, vol. 183, no. 4, pp. 1079-1083, 2004.

[39] J. H. Ellis, C. Tempany, M. S. Sarin, C. Gatsonis, M. D. Rifkin, and B. J. McNeil, "MR imaging and sonography of early prostatic cancer: pathologic and imaging features that influence identification and diagnosis," American Journal of Roentgenology, vol. 162, no. 4, pp. 865-872, 1994.

[40] O. Akin, E. Sala, C. S. Moskowitz, et al., "Transition zone prostate cancers: features, detection, localization, and staging at endorectal MR imaging," Radiology, vol. 239, no. 3, pp. 784-792, 2006.

[41] J. Comet-Batlle, J. C. Vilanova-Busquets, J. M. Saladié-Roig, A. Gelabert-Mas, C. Barceló-Vidal, and J. A. Spencer, "The value of endorectal MRI in the early diagnosis of prostate cancer," European Urology, vol. 44, no. 2, pp. 201-208, 2003.

[42] B. Djavan, V. Ravery, A. Zlotta, et al., "Prospective evaluation of prostate cancer detected on biopsies 1,2,3 and 4: when should we stop?" Journal of Urology, vol. 166, pp. 1679-1683, 2001.

[43] A. B. Cheikh, N. Girouin, M. Colombel, et al., "Evaluation of T2-weighted and dynamic contrast-enhanced MRI in localizing prostate cancer before repeat biopsy," European Radiology, vol. 19, no. 3, pp. 770-778, 2009.

[44] D. Beyersdorff, A. Winkel, B. Hamm, S. Lenk, S. A. Loening, and M. Taupitz, "MR imaging-guided prostate biopsy with a closed MR unit at 1.5 T: initial results," Radiology, vol. 234, no. 2, pp. 576-581, 2005.

[45] K. M. Pondman, J. J. Fütterer, B. ten Haken, et al., "MRguided biopsy of the prostate: an overview of techniques and a systematic review," European Urology, vol. 54, no. 3, pp. 517-527, 2008.

[46] H. Hricak, L. Wang, D. C. Wei, et al., "The role of preoperative endorectal magnetic resonance imaging in the decision regarding whether to preserve or resect neurovascular bundles during radical retropubic prostatectomy," Cancer, vol. 100, no. 12, pp. 2655-2663, 2004.

[47] A. P. Labanaris, V. Zugor, S. Takriti, et al., "The role of conventional and functional endorectal magnetic resonance imaging in the decision of whether to preserve or resect the neurovascular bundles during radical retropubic prostatectomy," Scandinavian Journal of Urology and Nephrology, vol. 43, no. 1, pp. 25-31, 2009.

[48] F. V. Coakley, S. Eberhardt, D. C. Wei, et al., "Blood loss during radical retropubic prostatectomy: relationship to morphologic features on preoperative endorectal magnetic resonance imaging," Urology, vol. 59, no. 6, pp. 884-888, 2002.

[49] K. K. Yu, J. Scheidler, H. Hricak, et al., "Prostate cancer: prediction of extracapsular extension with endorectal MR imaging and three-dimensional proton MR spectroscopic imaging," Radiology, vol. 213, no. 2, pp. 481-488, 1999.

[50] G. J. Jager, E. T. G. Ruijter, et al., "Local staging of prostate cancer with endorectal MRI: correlation with histopathology," American Journal of Roentgenology, vol. 166, pp. 845852, 1996.

[51] C. K. Kim, B. K. Park, and B. Kim, "Localization of prostate cancer using 3T MRI. Comparison of T2-weighted and dynamic contrast-enhanced imaging," Journal of Computer Assisted Tomography, vol. 30, no. 1, pp. 7-11, 2006.

[52] A. O. Sartor, H. Hricak, et al., "Evaluating localized Pca and identifying candidates for focal therapy," The Journal of Urology, vol. 72, supplement 6A, pp. 12-24, 2008.

[53] J. J. Fütterer, J. O. Barentsz, and S. W. Heijmink, "Value of 3-T magnetic resonance imaging in local staging of prostate cancer," Topics in Magnetic Resonance Imaging, vol. 19, no. 6, pp. 285-289, 2008.

[54] M. Mullerad, H. Hricak, L. Wang, et al., "PCa: detection of extracapsular extension by GU and general body radiologists at MR imaging," Radiology, vol. 232, pp. 133-139, 2004.

[55] C. M. Tempany, X. Zhou, E. A. Zerhouni, et al., "Staging of prostate cancer: results of Radiology Diagnostic Oncology Group project comparison of three MR imaging techniques," Radiology, vol. 192, no. 1, pp. 47-54, 1994.

[56] M. D. Rifkin, E. A. Zerhouni, C. A. Gatsonis, et al., "Comparison of magnetic resonance imaging and ultrasonography in staging early prostate cancer. Results of a multi-institutional cooperative trial," The New England Journal of Medicine, vol. 323, no. 10, pp. 621-626, 1990.

[57] J. S. Wolf Jr., M. Cher, M. Dall'Era, J. C. Presti Jr., H. Hricak, and P. R. Carroll, "The use and accuracy of cross-sectional imaging and fine needle aspiration cytology for detection of pelvic lymph node metastases before radical prostatectomy," Journal of Urology, vol. 153, no. 3, pp. 993-999, 1995.

[58] H. Hricak, S. White, D. Vigneron, et al., "Carcinoma of the prostate gland: MR imaging with pelvic phased-array coils versus integrated endorectal-pelvic phased-array coils," Radiology, vol. 193, no. 3, pp. 703-709, 1994.

[59] L. Wang, M. Mullerad, H.-N. Chen, et al., "Prostate cancer: incremental value of endorectal MR imaging findings for prediction of extracapsular extension,” Radiology, vol. 232, no. 1, pp. 133-139, 2004.

[60] M. R. Engelbrecht, G. J. Jager, R. J. Laheij, A. L. M. Verbeek, H. J. van Lier, and J. O. Barentsz, "Local staging of prostate 
cancer using magnetic resonance imaging: a meta-analysis," European Radiology, vol. 12, no. 9, pp. 2294-2302, 2002.

[61] S. S. Sonnad, C. P. Langlotz, and J. S. Schwartz, "Accuracy of MR imaging for staging prostate cancer: a meta-analysis to examine the effect of technologic change," Academic Radiology, vol. 8, no. 2, pp. 149-157, 2001.

[62] P. Torricelli, F. Cinquantini, G. Ligabue, G. Bianchi, P. Sighinolfi, and R. Romagnoli, "Comparative evaluation between external phased array coil at $3 \mathrm{~T}$ and endorectal coil at 1.5 T: preliminary results," Journal of Computer Assisted Tomography, vol. 30, no. 3, pp. 355-361, 2006.

[63] J. J. Fütterer, M. R. Engelbrecht, G. J. Jager, et al., "Prostate cancer: comparison of local staging accuracy of pelvic phased-array coil alone versus integrated endorectal-pelvic phased-array coils," European Radiology, vol. 17, no. 4, pp. 1055-1065, 2007.

[64] A. Graser, A. Heuck, B. Sommer, et al., "Per-sextant localization and staging of prostate cancer: correlation of imaging findings with whole-mount step section histopathology," American Journal of Roentgenology, vol. 188, no. 1, pp. 84-90, 2007.

[65] S. W. Heijmink, J. J. Fütterer, T. Hambrock, et al., "Prostate cancer: body array versus endorectal coil MR imaging at 3T-comparison of image quality, localization, and staging performance," Radiology, vol. 244, no. 1, pp. 184-195, 2007.

[66] J. J. Fütterer, S. W. Heijmink, T. W. J. Scheenen, et al., "Prostate cancer: local staging at 3-T endorectal MR imaging-early experience," Radiology, vol. 238, no. 1, pp. 184-191, 2006.

[67] L. Wang, H. Hricak, M. W. Kattan, H.-N. Chen, P. T. Scardino, and K. Kuroiwa, "Prediction of organ-confined prostate cancer: incremental value of MR imaging and MR spectroscopic imaging to staging nomograms," Radiology, vol. 238, no. 2, pp. 597-603, 2006.

[68] M. R. Engelbrecht, G. J. Jager, and J. L. Severens, "Patient selection for magnetic resonance imaging of prostate cancer," European Urology, vol. 40, no. 3, pp. 300-307, 2001.

[69] F. L. Green, D. L. Page, I. D. Fleming, et al., AJCC Cancer Staging Manual, Springer, New York, NY, USA, 2002.

[70] A. V. D'Amico, R. Whittington, B. Malkowicz, et al., "Endorectal magnetic resonance imaging as a predictor of biochemical outcome after radical prostatectomy in men with clinically localized prostate cancer," Journal of Urology, vol. 164, no. 3, pp. 759-763, 2000.

[71] F. May, T. Treumann, P. Dettmar, R. Hartung, and J. Breul, "Limited value of endorectal magnetic resonance imaging and transrectal ultrasonography in the staging of clinically localized prostate cancer," BJU International, vol. 87 , no. 1 , pp. 66-69, 2001.

[72] C. Testa, R. Schiavina, R. Lodi, et al., "Prostate cancer: sextant localization with MR imaging, MR spectroscopy, and ${ }^{11} \mathrm{C}$ choline PET/CT," Radiology, vol. 244, no. 3, pp. 797-806, 2007.

[73] J. Scheidler, H. Hricak, D. B. Vigneron, et al., "Prostate cancer: localization with three-dimensional proton MR spectroscopic imaging — clinicopathologic study," Radiology, vol. 213, no. 2, pp. 473-480, 1999.

[74] J. Scheidler, H. Hricak, D. B. Vigneron, et al., "Prostate cancer: localization with three-dimensional proton MR spectroscopic imaging — clinicopathologic study," Radiology, vol. 213, no. 2, pp. 473-480, 1999.

[75] A. Shukla-Dave, H. Hricak, M. W. Kattan, et al., "The utility of magnetic resonance imaging and spectroscopy for predicting insignificant prostate cancer: an initial analysis," BJU International, vol. 99, no. 4, pp. 786-793, 2007.

[76] F. V. Coakley, J. Kurhanewicz, Y. Lu, et al., "Prostate cancer tumor volume: measurement with endorectal MR and MR spectroscopic imaging," Radiology, vol. 223, no. 1, pp. 91-97, 2002.

[77] J. C. Weinreb, J. D. Blume, F. V. Coakley, et al., "Prostate cancer: sextant localization at MR imaging and MR spectroscopic imaging before prostatectomy-results of ACRIN prospective multi-institutional clinicopathologic study," Radiology, vol. 251, no. 1, pp. 122-133, 2009.

[78] K. L. Zakian, K. Sircar, H. Hricak, et al., "Correlation of proton MR spectroscopic imaging with gleason score based on step-section pathologic analysis after radical prostatectomy," Radiology, vol. 234, no. 3, pp. 804-814, 2005.

[79] D. Pucar, A. Shukla-Dave, H. Hricak, et al., "Prostate cancer: correlation of MR imaging and MR spectroscopy with pathologic findings after radiation therapy-iInitial experience," Radiology, vol. 236, no. 2, pp. 545-553, 2005.

[80] J. C. Vilanova and J. Barceló, "Prostate cancer detection: magnetic resonance (MR) spectroscopic imaging," Abdominal Imaging, vol. 32, no. 2, pp. 253-261, 2007.

[81] F. Parivar, H. Hricak, K. Shinohara, et al., "Detection of locally recurrent prostate cancer after cryosurgery: evaluation by transrectal ultrasound, magnetic resonance imaging, and three- dimensional proton magnetic resonance spectroscopy,” Urology, vol. 48, no. 4, pp. 594-599, 1996.

[82] R. Alonzi, A. R. Padhani, and C. Allen, "Dynamic contrast enhanced MRI in prostate cancer," European Journal of Radiology, vol. 63, no. 3, pp. 335-350, 2007.

[83] M.-C. Bettencourt, J. J. Bauer, I. A. Sesterhenn, R. R. Connelly, and J. W. Moul, "CD34 immunohistochemical assessment of angiogenesis as a prognostic marker for prostate cancer recurrence after radical prostatectomy," Journal of Urology, vol. 160, no. 2, pp. 459-465, 1998.

[84] G. Brown, D. A. Macvicar, V. Ayton, and J. E. Husband, "The role of intravenous contrast enhancement in magnetic resonance imaging of prostatic carcinoma," Clinical Radiology, vol. 50, no. 9, pp. 601-606, 1995.

[85] G. J. Jager, E. T. G. Ruijter, C. A. van de Kaa, et al., "Dynamic TurboFLASH subtraction technique for contrast-enhanced MR imaging of the prostate: correlation with histopathologic results," Radiology, vol. 203, no. 3, pp. 645-652, 1997.

[86] H.-P. Schlemmer, J. Merkle, R. Grobholz, et al., "Can pre-operative contrast-enhanced dynamic MR imaging for prostate cancer predict microvessel density in prostatectomy specimens?" European Radiology, vol. 14, no. 2, pp. 309-317, 2004.

[87] N. Hara, M. Okuizumi, H. Koike, M. Kawaguchi, and V. Bilim, "Dynamic contrast-enhanced magnetic resonance imaging (DCE-MRI) is a useful modality for the precise detection and staging of early prostate cancer," Prostate, vol. 62, no. 2, pp. 140-147, 2005.

[88] S. Muramoto, H. Uematsu, H. Kimura, et al., "Differentiation of prostate cancer from benign prostate hypertrophy using dual-echo dynamic contrast MR imaging," European Journal of Radiology, vol. 44, no. 1, pp. 52-58, 2002.

[89] H. Ito, K. Kamoi, K. Yokoyama, K. Yamada, and T. Nishimura, "Visualization of prostate cancer using dynamic contrast-enhanced MRI: comparison with transrectal power Doppler ultrasound," The British Journal of Radiology, vol. 76, no. 909, pp. 617-624, 2003.

[90] B. N. Bloch, E. Furman-Haran, T. H. Helbich, et al., "Prostate cancer: accurate determination of extracapsular extension 
with high-spatial-resolution dynamic contrast-enhanced and T2-weighted MR imaging-initial results," Radiology, vol. 245, no. 1, pp. 176-185, 2007.

[91] K. Ogura, S. Maekawa, K. Okubo, et al., "Dynamic endorectal magnetic resonance imaging for local staging and detection of neurovascular bundle involvement of prostate cancer: correlation with histopathologic results," Urology, vol. 57, no. 4, pp. 721-726, 2001.

[92] J. J. Fütterer, S. W. Heijmink, T. W. J. Scheenen, et al., "Prostate cancer localization with dynamic contrastenhanced MR imaging and proton MR spectroscopic imaging," Radiology, vol. 241, no. 2, pp. 449-458, 2006.

[93] T. Namimoto, S. Morishita, R. Saitoh, J. Kudoh, Y. Yamashita, and M. Takahashi, "The value of dynamic MR imaging for hypointensity lesions of the peripheral zone of the prostate," Computerized Medical Imaging and Graphics, vol. 22, no. 3, pp. 239-245, 1998.

[94] J. H. Mydlo, J. G. Kral, M. Volpe, C. Axotis, R. J. Macchia, and L. P. Pertschuk, "An analysis of microvessel density, androgen receptor, p53 and HER-2/neu expression and Gleason score in prostate cancer. Preliminary results and therapeutic implications," European Urology, vol. 34, no. 5, pp. 426-432, 1998.

[95] A. A. Sinha, B. J. Quast, P. K. Reddy, et al., "Microvessel density as a molecular marker for identifying high-grade prostatic intraepithelial neoplasia precursors to prostate cancer," Experimental and Molecular Pathology, vol. 77, no. 2, pp. 153-159, 2004.

[96] A. R. Padhani, C. J. Gapinski, D. A. Macvicar, et al., "Dynamic contrast enhanced MRI of prostate cancer: correlation with morphology and tumour stage, histological grade and PSA," Clinical Radiology, vol. 55, no. 2, pp. 99-109, 2000.

[97] C. K. Kim and B. K. Park, "Update of prostate MRI at 3T," Journal of Computer Assisted Tomography, vol. 32, no. 2, pp. 163-172, 2008.

[98] J. J. Fütterer, T. W. J. Scheenen, H. J. Huisman, et al., "Initial experience of 3 tesla endorectal coil magnetic resonance imaging and $1 \mathrm{H}$-spectroscopic imaging of the prostate," Investigative Radiology, vol. 39, no. 11, pp. 671-680, 2004.

[99] L. W. Turnbull, D. L. Buckley, L. S. Turnbull, G. P. Liney, and A. J. Knowles, "Differentiation of prostatic carcinoma and benign prostatic hyperplasia: correlation between dynamic Gd-DTPA-enhanced MR imaging and histopathology," Journal of Magnetic Resonance Imaging, vol. 9, no. 2, pp. 311-316, 1999.

[100] M. A. Jacobs, R. Ouwerkerk, K. Petrowski, and K. J. MacUra, "Diffusion-weighted imaging with apparent diffusion coefficient mapping and spectroscopy in prostate cancer," Topics in Magnetic Resonance Imaging, vol. 19, no. 6, pp. 261-272, 2008.

[101] B. Issa, "In vivo measurement of the apparent diffusion coefficient in normal and malignant prostatic tissues using echoplanar imaging," Journal of Magnetic Resonance Imaging, vol. 16, no. 2, pp. 196-200, 2002.

[102] C. Sato, S. Naganawa, T. Nakamura, et al., "Differentiation of noncancerous tissue and cancer lesion by apparent diffusion coefficient values in transition and peripheral zones of the prostate," Journal of Magnetic Resonance Imaging, vol. 21, no. 3, pp. 258-262, 2005.

[103] Y. Mazaheri, A. Shukla-Dave, H. Hricak, et al., "Prostate cancer: identification with combined diffusion-weighted MR imaging and 3D1H MR spectroscopic imaging — correlation with pathologic findings," Radiology, vol. 246, no. 2, pp. 480488, 2008.
[104] A. Tanimoto, J. Nakashima, H. Kohno, H. Shinmoto, and S. Kuribayashi, "Prostate cancer screening: the clinical value of diffusion-weighted imaging and dynamic MR imaging in combination with T2-weighted imaging," Journal of Magnetic Resonance Imaging, vol. 25, no. 1, pp. 146-152, 2007.

[105] C. K. Kim, B. K. Park, and H. M. Lee, "Prediction of locally recurrent prostate cancer after radiation therapy: incremental value of 3T diffusion-weighted MRI," Journal of Magnetic Resonance Imaging, vol. 29, no. 2, pp. 391-397, 2009.

[106] Y. Mazaheri, H. Hricak, S. W. Fine, et al., "Prostate tumor volume measurement with combined T2-weighted imaging and diffusion-weighted MR: correlation with pathologic tumor volume," Radiology, vol. 252, no. 2, pp. 449-457, 2009.

[107] B. K. Park, H. M. Lee, C. K. Kim, H. Y. Choi, and J. W. Park, "Lesion localization in patients with a previous negative transrectal ultrasound biopsy and persistently elevated prostate specific antigen level using diffusion-weighted imaging at three tesla before rebiopsy," Investigative Radiology, vol. 43, no. 11, pp. 789-793, 2008.

[108] C. K. Kim, B. K. Park, J. J. Han, T. W. Kang, and H. M. Lee, "Diffusion-weighted imaging of the prostate at 3 $\mathrm{T}$ for differentiation of malignant and benign tissue in transition and peripheral zones: preliminary results," Journal of Computer Assisted Tomography, vol. 31, no. 3, pp. 449-454, 2007.

[109] J. O. Barentsz, J. J. Fütterer, and S. Takahashi, "Use of ultrasmall superparamagnetic iron oxide in lymph node MR imaging in prostate cancer patients," European Journal of Radiology, vol. 63, no. 3, pp. 369-372, 2007.

[110] M. G. Harisinghani, J. Barentsz, P. F. Hahn, et al., "Noninvasive detection of clinically occult lymph-node metastases in prostate cancer," The New England Journal of Medicine, vol. 348, no. 25, pp. 2491-2499, 2003.

[111] R. W. Ross, A. L. Zietman, W. Xie, et al., "Lymphotropic nanoparticle-enhanced magnetic resonance imaging (LNMRI) identifies occult lymph node metastases in prostate cancer patients prior to salvage radiation therapy," Clinical Imaging, vol. 33, no. 4, pp. 301-305, 2009.

[112] R. H. Oyen, H. P. van Poppel, F. E. Ameye, W. A. Van De Voorde, A. L. Baert, and L. V. Baert, "Lymph node staging of localized prostatic carcinoma with CT and CT-guided fineneedle aspiration biopsy: prospective study of 285 patients," Radiology, vol. 190, no. 2, pp. 315-322, 1994.

[113] J. W. Walsh, M. A. Amendola, et al., "CT detection of pelvic and inguinal LN metastases from primary and recurrent pelvic malignant disease," Radiology, vol. 137, pp. 157-166, 1980.

[114] G. J. O’Dowd, R. W. Veltri, R. Orozco, M. C. Miller, and J. E. Oesterling, "Update on the appropriate staging evaluation for newly diagnosed prostate cancer," Journal of Urology, vol. 158, no. 3, pp. 687-698, 1997.

[115] J. W. Walsh, M. A. Amendola, and K. F. Konerding, "Computed tomographic detection of pelvic and inguinal lymph-node metastases from primary and recurrent pelvic malignant disease," Radiology, vol. 137, no. 1, pp. 157-166, 1980.

[116] J. Rørvik, O. J. Halvorsen, G. Albrektsen, and S. Haukaas, "Lymphangiography combined with biopsy and computer tomography to detect lymph node metastases in localized prostate cancer," Scandinavian Journal of Urology and Nephrology, vol. 32, no. 2, pp. 116-119, 1998.

[117] J. S. Wolf Jr., M. Cher, M. Dall'Era, J. C. Presti Jr., H. Hricak, and P. R. Carroll, "The use and accuracy of cross-sectional 
imaging and fine needle aspiration cytology for detection of pelvic lymph node metastases before radical prostatectomy," Journal of Urology, vol. 153, no. 3, pp. 993-999, 1995.

[118] I. J. Liu, M. B. Zafar, Y.-H. Lai, G. M. Segall, and M. K. Terris, "Fluorodeoxyglucose positron emission tomography studies in diagnosis and staging of clinically organ-confined prostate cancer," Urology, vol. 57, no. 1, pp. 108-111, 2001.

[119] C. Hofer, C. Laubenbacher, T. Block, J. Breul, R. Hartung, and M. Schwaiger, "Fluorine-18-fluorodeoxyglucose positron emission tomography is useless for the detection of local recurrence after radical prostatectomy," European Urology, vol. 36, no. 1, pp. 31-35, 1999.

[120] P. J. Effert, R. Bares, S. Handt, J. M. Wolff, U. Büll, and G. Jakse, "Metabolic imaging of untreated prostate cancer by positron emission tomography with 18 fluorine-labeled deoxyglucose," Journal of Urology, vol. 155, no. 3, pp. 994998, 1996.

[121] P. D. Shreve, H. B. Grossman, M. D. Gross, and R. L. Wahl, "Metastatic prostate cancer: initial findings of PET with 2deoxy-2-[F-18]fluoro-D-glucose," Radiology, vol. 199, no. 3, pp. 751-756, 1996.

[122] J. Sung, J. I. Espiritu, G. M. Segall, and M. K. Terris, "Fluorodeoxyglucose positron emission tomography studies in the diagnosis and staging of clinically advanced prostate cancer," BJU International, vol. 92, no. 1, pp. 24-27, 2003.

[123] N. Oyama, H. Akino, Y. Suzuki, et al., "The increased accumulation of $[18 \mathrm{~F}]$ fluorodeoxyglucose in untreated prostate cancer," Japanese Journal of Clinical Oncology, vol. 29, no. 12, pp. 623-629, 1999.

[124] P. L. Jager, W. Vaalburg, J. Pruim, E. G. E. De Vries, K.-J. Langen, and D. A. Piers, "Radiolabeled amino acids: basic aspects and clinical applications in oncology," Journal of Nuclear Medicine, vol. 42, no. 3, pp. 432-445, 2001.

[125] D. T. Schmid, H. John, R. Zweifel, et al., "Fluorocholine PET/CT in patients with prostate cancer: initial experience," Radiology, vol. 235, no. 2, pp. 623-628, 2005.

[126] I. Igerc, S. Kohlfürst, H. J. Gallowitsch, et al., "The value of 18F-Choline PET/CT in patients with elevated PSA-level and negative prostate needle biopsy for localisation of prostate cancer," European Journal of Nuclear Medicine and Molecular Imaging, vol. 35, no. 5, pp. 976-983, 2008.

[127] R. Schiavina, V. Scattoni, P. Castellucci, et al., "11 C-choline positron emission tomography/computerized tomography for preoperative lymph-node staging in intermediate-risk and high-risk prostate cancer: comparison with clinical staging nomograms," European Urology, vol. 54, no. 2, pp. 392-401, 2008.

[128] D. B. Husarik, R. Miralbell, M. Dubs, et al., "Evaluation of [18F]-choline PET/CT for staging and restaging of prostate cancer," European Journal of Nuclear Medicine and Molecular Imaging, vol. 35, no. 2, pp. 253-263, 2008.

[129] K. Bouchelouche, J. Capala, and P. Oehr, "Positron emission tomography/computed tomography and radioimmunotherapy of prostate cancer," Current Opinion in Oncology, vol. 21, no. 5, pp. 469-474, 2009.

[130] L. Rinnab, F. M. Mottaghy, J. Simon, et al., " $\left[{ }^{11} \mathrm{C}\right]$ choline $\mathrm{PET} / \mathrm{CT}$ for targeted salvage lymph node dissection in patients with biochemical recurrence after primary curative therapy for prostate cancer: preliminary results of a prospective study," Urologia Internationalis, vol. 81, no. 2, pp. 191197,2008

[131] L. Rinnab, J. Simon, R. E. Hautmann, et al., " $\left[{ }^{11} \mathrm{C}\right]$ choline $\mathrm{PET} / \mathrm{CT}$ in prostate cancer patients with biochemical recurrence after radical prostatectomy," World Journal of Urology, vol. 27, no. 5, pp. 619-625, 2009.

[132] B. J. Krause, M. Souvatzoglou, M. Tuncel, et al., "The detection rate of $\left[{ }^{11} \mathrm{C}\right]$ choline-PET/CT depends on the serum PSA-value in patients with biochemical recurrence of prostate cancer," European Journal of Nuclear Medicine and Molecular Imaging, vol. 35, no. 1, pp. 18-23, 2008.

[133] S. N. Reske, N. M. Blumstein, and G. Glatting, " $\left[{ }^{11} \mathrm{C}\right]$ choline PET/CT imaging in occult local relapse of prostate cancer after radical prostatectomy," European Journal of Nuclear Medicine and Molecular Imaging, vol. 35, no. 1, pp. 9-17, 2008.

[134] R. Nuñez, H. A. Macapinlac, H. W. D. Yeung, et al., "Combined 18F-FDG and ${ }^{11} \mathrm{C}$-methionine PET scans in patients with newly progressive metastatic prostate cancer," Journal of Nuclear Medicine, vol. 43, no. 1, pp. 46-55, 2002.

[135] J. A. Richter, M. Rodríguez, J. Rioja, et al., "Dual tracer ${ }^{11} \mathrm{C}$-choline and FDG-PET in the diagnosis of biochemical prostate cancer relapse after radical treatment," Molecular Imaging and Biology. In press.

[136] U. Elsässer-Beile, G. Reischl, S. Wiehr, et al., "PET imaging of prostate cancer xenografts with a highly specific antibody against the prostate-specific membrane antigen," Journal of Nuclear Medicine, vol. 50, no. 4, pp. 606-611, 2009.

[137] R. C. Mease, C. L. Dusich, C. A. Foss, et al., "N-[N-[(S)1,3-dicarboxypropyl]carbamoyl]-4-[18F]fluorobenzyl-Lcysteine, [18F]DCFBC: a new imaging probe for prostate cancer," Clinical Cancer Research, vol. 14, no. 10, pp. 3036-3043, 2008.

[138] "Food and Drug Administration Product Approval Letter: capromab pendetide," October 1996, http://www.fda.gov/ Drugs/DevelopmentApprovalProcess/HowDrugsareDevelopedandApproved/ApprovalApplications/TherapeuticBiologic Applications/ucm080734.htm.

[139] D. Kahn, R. D. Williams, M. J. Manyak, et al., "111indiumcapromab pendetide in the evaluation of patients with residual or recurrent prostate cancer after radical prostatectomy," Journal of Urology, vol. 159, no. 6, pp. 2041-2047, 1998.

[140] M. A. Seltzer, Z. Barbaric, A. Belldegrun, et al., "Comparison of helical computerized tomography, positron emission tomography and monoclonal antibody scans for evaluation of lymph node metastases in patients with prostate specific antigen relapse after treatment for localized prostate cancer," Journal of Urology, vol. 162, no. 4, pp. 1322-1328, 1999.

[141] S. N. Nagda, N. Mohideen, S. S. Lo, et al., "Long-term follow-up of 111 In-capromab pendetide (ProstaScint) scan as pretreatment assessment in patients who undergo salvage radiotherapy for rising prostate-specific antigen after radical prostatectomy for prostate cancer," International Journal of Radiation Oncology Biology Physics, vol. 67, no. 3, pp. 834840, 2007.

[142] J. K. Troyer, M. L. Beckett, and G. L. Wright Jr., "Location of prostate-specific membrane antigen in the LNCaP prostate carcinoma cell line," Prostate, vol. 30, no. 4, pp. 232-242, 1997.

[143] S. S. Chang, V. E. Reuter, W. D. W. Heston, N. H. Bander, L. S. Grauer, and P. B. Gaudin, "Five different anti-prostatespecific membrane antigen (PSMA) antibodies confirm PSMA expression in tumor-associated neovasculature," Cancer Research, vol. 59, no. 13, pp. 3192-3198, 1999. 


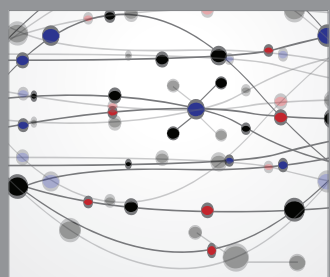

The Scientific World Journal
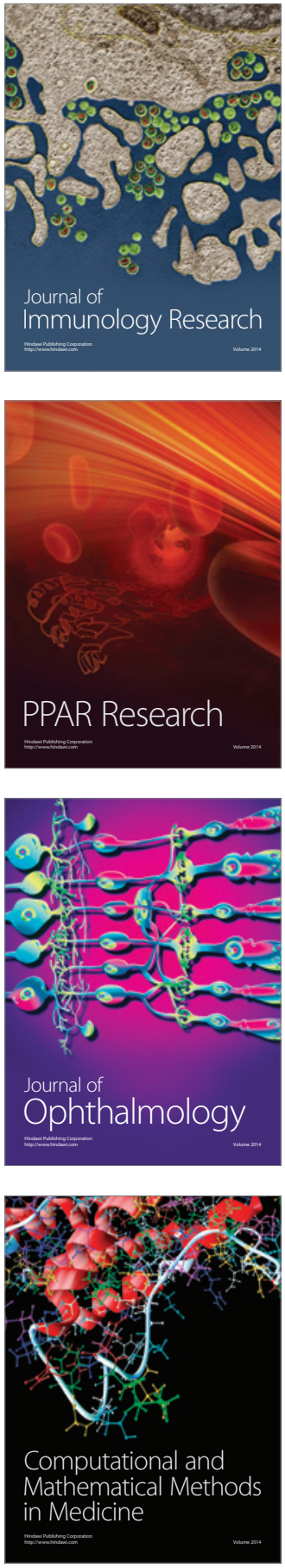

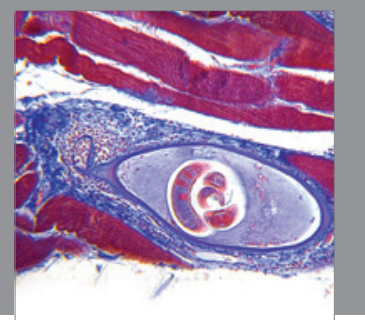

Gastroenterology

Research and Practice
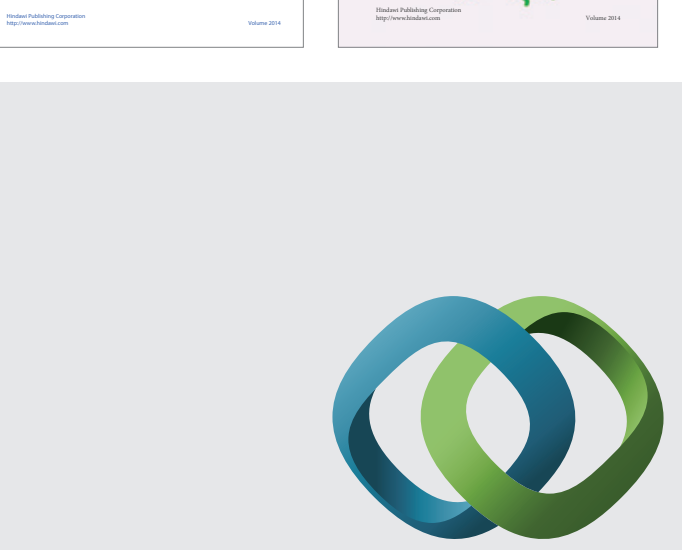

\section{Hindawi}

Submit your manuscripts at

http://www.hindawi.com
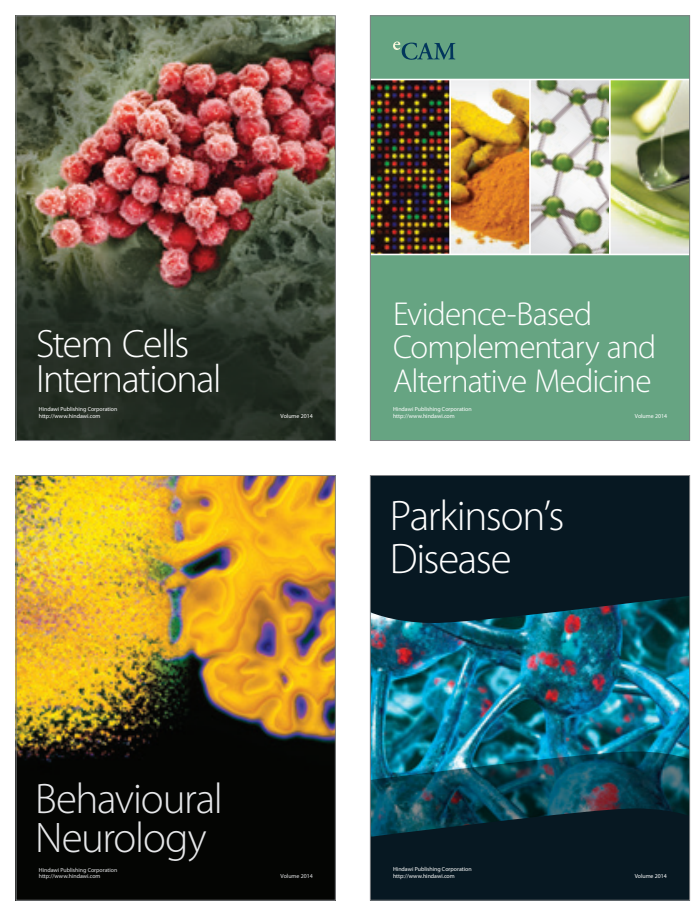

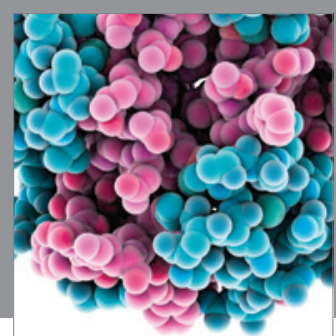

Journal of
Diabetes Research

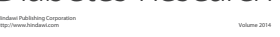

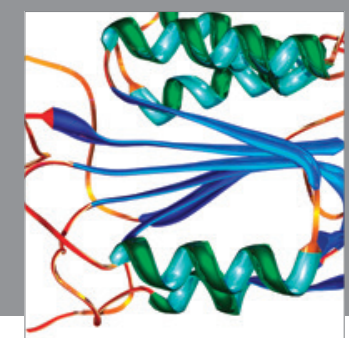

Disease Markers
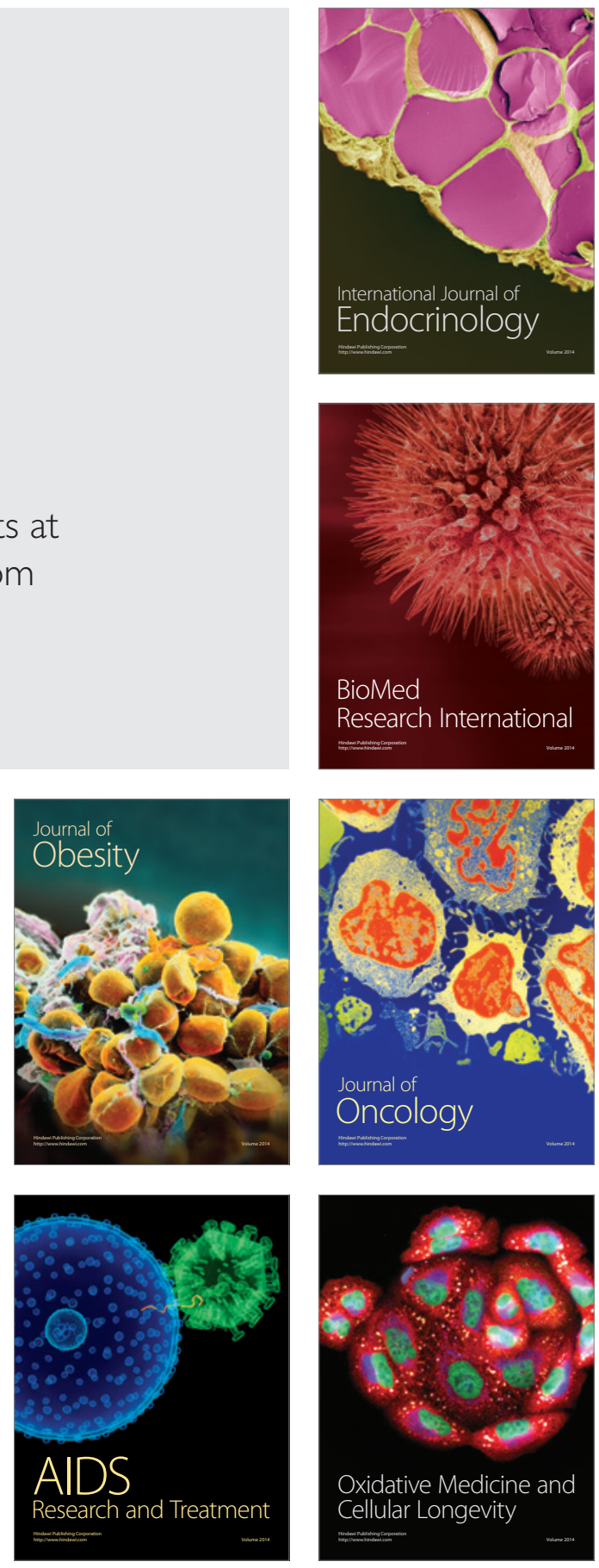